\title{
Designing video feedback to support the socioemotional aspects of online learning
}

\author{
$\operatorname{Tracii}_{\text {Ryan }^{1}}{ }^{\mathbb{D}}$
}

Accepted: 19 November 2020 / Published online: 11 January 2021

(c) Association for Educational Communications and Technology 2021

\begin{abstract}
The COVID-19 pandemic required instructors to rapidly redesign subject delivery for the online environment. In dealing with this emergency situation, instructors may have focused their energies primarily on transitioning learning and assessment activities to the online context rather than working to support the socioemotional aspects of learning, such as belonging and motivation. As a result, online classes may have lacked social presence, leaving students feeling unvalued and demotivated. Research findings by Borup, West, and Thomas (Educ Technol Res Dev 63(2):161-184, 2015) indicate that instructors may be able to support positive socioemotional outcomes for online students through the provision of video feedback comments. The purpose of this short response is to briefly review the work of Borup et al. (2015) and, in doing so, highlight three key design considerations relating to the creation and provision of video feedback comments in order to bolster socioemotional outcomes for online students. Limitations and implications for future research are also discussed, including cultural and inclusivity issues.
\end{abstract}

Keywords Video feedback $\cdot$ Higher education $\cdot$ Belonging $\cdot$ Motivation

When designing for online learning in higher education, it is critical for instructors to consider how to support positive socioemotional outcomes for students, such as a sense of belonging to the learning community (Crow \& Murray, 2020; Delahunty, Verenikina, \& Jones, 2014). This is because online learning is more distributed, socially isolated, and asynchronous than its face-to-face counterpart (Lowenthal \& Dennen, 2017), and students have fewer opportunities for sustained synchronous social interactivity with peers or instructors. This may reduce social presence (Crow \& Murray, 2020), and risk leaving online students feeling anonymous, unvalued, and demotivated (Delahunty et al., 2014; Plante \& Asselin, 2014).

The COVID-19 pandemic forced face-to-face instructors to rapidly redesign subject delivery for the online environment (Lederman, 2020). In dealing with this emergency

Tracii Ryan

tracii.ryan@unimelb.edu.au

1 Melbourne Centre for the Study of Higher Education, Melbourne Graduate School of Education, The University of Melbourne, Elisabeth Murdoch Building, Spencer Road, Parkville, VIC 3010, Australia 
situation, these instructors are likely to have focused primarily on successfully transitioning face-to-face learning and assessment activities to the online context (Hill, 2020). As such, they may have had lacked capacity to consider how best to support the socioemotional aspects of learning in this new environment (Heitz, Laboissiere, Sanghvi, \& Sarakatsannis, 2020). Perhaps unsurprisingly, anecdotal evidence suggests that many students who made the rapid mandated shift to online learning experienced feelings of displacement, social isolation, and demotivation (Hall \& Batty, 2020; Yamin, 2020). For some students, these feelings may have been exacerbated by anxiety associated with the pandemic.

According to a study by Borup, West, and Thomas (2015), instructors may be able to bolster socioemotional outcomes for students by making relatively simple design choices in relation to assessment feedback. More specifically, the study found that online students felt more supported, valued and encouraged when instructors provided assessment feedback in the form of asynchronous video recordings rather than text (for a more detailed review of the cognitive and socioemotional impacts of video feedback, see Mahoney, Macfarlane, \& Ajjawi, 2019). The socioemotional affordances of video feedback can be interpreted in terms of media richness theory (Daft \& Lengel, 1986), which argues that video feedback conveys rich conversational cues that are not available in text, such as tone and pace of voice, facial expressions and body language. The purpose of this short response is to briefly review the work of Borup et al. (2015), and in doing so, highlight three key design considerations for the use of video feedback to support positive socioemotional impacts (for additional design considerations relating to video feedback, see Thomas, West, \& Borup, 2017).

First, video feedback can and should feature qualitatively different messages than textbased feedback. Content analysis conducted by Borup et al. (2015) showed that text-based feedback tended to feature comments that highlighted specific strengths, weaknesses, and areas of improvement in relation to the task. In contrast, video feedback more frequently included general and specific praise for the students' work, as well comments aimed at strengthening the relationship between the instructor and student (e.g., use of the student's name). As shown in the broader feedback and online learning literature, both praise and relational comments are useful for improving social presence, strengthening feelings of trust, and helping students feel supported and motivated (Plante \& Asselin, 2014; Yang \& Carless, 2013).

Second, the use of video feedback should be timed judiciously within the teaching period. Borup et al. (2015) and others (e.g., Crow \& Murray, 2020) argue that it is important for instructors to foster a sense of community and belonging in the first few weeks of the teaching period. Furthermore, students may obtain a greater sense of value, support, and social presence when feedback on assessment tasks is provided in a timely manner (Crow \& Murray, 2020; Plante \& Asselin, 2014); in their study, Borup et al. (2015) asked instructors to return feedback comments no more than 1 week after assessment submission. Therefore, in the context of a rapid shift to online learning, students may feel more valued and motivated if they received short, personalised, and positively framed video feedback recordings soon after the shift occurs (e.g., a week after submission of the next assessment task following the shift).

Third, video feedback may be more impactful for certain types of students than others. For example, students who are generally moderate-to-high achievers, but who have performed poorly on an assessment task after the rapid shift to online learning (presumably due to health or wellbeing issues) may benefit from the more personalised and supportive style of communication that video feedback affords (Borup et al., 2015). In these circumstances, Borup et al. (2015) argue that it is important for instructors to be highly cognizant 
of keeping their body language, expression, and tone of voice positive, so as not to unintentionally convey information that could be interpreted as negative or discouraging.

These three design considerations offer instructors guidance for the creation of video feedback recordings in the context of the rapid shift to online learning caused by COVID19. However, there are two main limitations of the study by Borup et al. (2015) that should be addressed. First, the study was performed across several blended delivery subjects, where students also had the option to attend face-to-face classes. This context differs from the response to the COVID-19 pandemic, where online learning and social isolation was unexpected and mandated. Further research is therefore needed to examine the efficacy of the design considerations discussed here in wholly online environments, particularly in situations where both instructors and students had expected to be working in face-to-face modes of delivery. Second, the authors failed to measure the perception and opinions of students from equity groups or diverse cultural backgrounds, or those who had accessibility issues, English-language challenges, or special learning needs. In fact, this is a widespread limitation of the video feedback literature in general, and is deserving of further empirical attention. In particular, additional qualitative studies are needed to explicate whether there are unique needs, perceptions, and preferences among these types of students in relation to online learning and video feedback, and whether their socioemotional needs when studying online differ from the rest of the cohort.

\section{Compliance with ethical standards}

conflicts of interest The authors have no conflicts of interest to disclose.

Research involving human participants and/or animals This research did not involve human or animal participants.

Informed consent This research did not involve human or animal participants.

\section{References}

Borup, J., West, R. E., \& Thomas, R. (2015). The impact of text versus video communication on instructor feedback in blended courses. Educational Technology Research and Development, 63(2), 161-184. https://doi.org/10.1007/s11423-015-9367-8.

Crow, J., \& Murray, J.-A. (2020). Online distance learning in biomedical sciences: Community, belonging and presence. In P. Rea (Ed.), Biomedical visualisation. Advances in experimental medicine and biology (Vol. 1235). Cham: Springer. https://doi.org/10.1007/978-3-030-37639-0_10.

Daft, R. L., \& Lengel, R. H. (1986). Organizational information requirements, media richness and structural design. Management Science, 32(5), 554-571. https://doi.org/10.1287/mnsc.32.5.554.

Delahunty, J., Verenikina, I., \& Jones, P. (2014). Socio-emotional connections: Identity, belonging and learning in online interactions. A literature review. Technology, Pedagogy and Education, 23(2), 243265. https://doi.org/10.1080/1475939X.2013.813405.

Hall, R., \& Batty, D. (2020, 4 May). 'I can't get motivated': The students struggling with online learning. The Guardian. Retrieved from https:/www.theguardian.com/education/2020/may/04/i-cant-get-motiv ated-the-students-struggling-with-online-learning.

Heitz, C., Laboissiere, M., Sanghvi, S., \& Sarakatsannis, J. (2020). Getting the next phase of remote learning right in higher education. McKinsey \& Company. Retrieved from https://www.mckinsey.com/ industries/public-sector/our-insights/getting-the-next-phase-of-remote-learning-right-in-higher-educa tion. 
Hill, P. (2020). Revised outlook for higher ed's online response to COVID-19. Retrieved from https://philo nedtech.com/revised-outlook-for-higher-eds-online-response-to-covid-19/.

Lederman, D. (2020). Will shift to remote teaching be boon or bane for online learning? Inside Higher Ed. Retrieved from https://www.insidehighered.com/digital-learning/article/2020/03/18/most-teachinggoing-remote-will-help-or-hurt-online-learning.

Lowenthal, P. R., \& Dennen, V. P. (2017). Social presence, identity, and online learning: Research development and needs. Distance Education, 38(2), 137-140. https://doi.org/10.1080/01587919.2017.13351 72.

Mahoney, P., Macfarlane, S., \& Ajjawi, R. (2019). A qualitative synthesis of video feedback in higher education. Teaching in Higher Education, Critical Perspectives, 24(2), 157-179. https://doi. org/10.1080/13562517.2018.1471457.

Plante, K., \& Asselin, M. E. (2014). Best practices for creating social presence and caring behaviors online. Nursing Education Perspectives, 35(4), 219-223. https://doi.org/10.5480/13-1094.1.

Thomas, R. A., West, R. E., \& Borup, J. (2017). An analysis of instructor social presence in online text and asynchronous video feedback comments. The Internet and Higher Education, 33, 61-73. https://doi. org/10.1016/j.iheduc.2017.01.003.

Yamin, K. (2020, 14 May). Mixed response but online classes to stay post COVID-19. University World News. Retrieved from https://www.universityworldnews.com/post.php?story=20200514121749886.

Yang, M., \& Carless, D. (2013). The feedback triangle and the enhancement of dialogic feedback processes. Teaching in Higher Education, Critical Perspectives, 18(3), 285-297. https://doi.org/10.1080/13562 517.2012.719154.

Publisher's Note Springer Nature remains neutral with regard to jurisdictional claims in published maps and institutional affiliations.

Tracii Ryan is a Research Fellow at the Melbourne Centre for the Study of Higher Education, Melbourne Graduate School of Education, University of Melbourne, Australia. Her research expertise bridges the disciplines of psychology and education, particularly in the areas of cyberpsychology, technology-enabled learning, feedback in higher education, and student wellbeing. 